\title{
O Leviathan declinante: a crise brasileira dos anos $\mathbf{8 0}$
}

\section{BRASILIO SALLUM JR.}

- EDUARDO KUGELMAS

s processos de transiçáo ocorridos na América Latina têm sido alvo de uma atenção particularmente concentrada da ciência política. Já existe uma ampla bibliografia sobre a dinâmica das transıçóes, enfatizando o papel de atores estratégicos, como empresários, sindicalistas e militares. Também foram sublinhadas as potencialidades analíticas abertas pela comparação com situações vistas como análogas, tais como as da Europa mediterrânea (1).

Ocupou lugar central nestas discussóes a longa e complexa transição brasileira, analisada ou até mesmo dissecada do ângulo acadêmico durante seu desenrolar. Por seu turno, a crise econômica dos anos 80, a década perdida, foi objeto de inúmeros estudos de economistas (2). No caso brasileiro, a aceleração da inflação e a centralidade política da discussão sobre planos de estabilização econômica deram o tom aos primeiros governos civis posteriores ao regime autoritário, o de José Sarney (1985-1990) e o de Fernando Collor de Mello (1990- ). A sucessão de planos econômicos frustrados condicionou o processo político em seu conjunto, lançando dúvidas e temores com relaçáo à própria consolidação das instituiçóes democráticas.

Certamente, ninguém ignora que a interação e o feedback entre os processos político e econômico constituem elemento central para a melhor compreensão de ambos. Porém, apesar de algumas referências quase rituais ao contexto institucional ou aos constrangimentos politicos, em textos de economistas, são raras ainda as tentativas verdadeiramente interdisciplinares na abordagem da temática da interação entre transição política e crise econômica (3).

Entre os trabalhos dos cientistas políticos, houve algumas tentativas dignas de registro no estabelecimento de um quadro de referência analítico que escapasse ao que Albert Hirschman denominou "seqüência cíclica simples e desoladora" (4). Esta seria a substituição de um regime militar autoritário por um governo democrático que não teria condiçōes de enfrentar o inevitável crescimento das demandas sociais. A aceleração inflacionária resultante desgastaria o novo regime, abrindo 
espaço a fortes pressóes pelo retorno do autoritarismo.

Esta expectativa pessimista certamente esteve presente nos cálculos dos atores políticos e sociais dos processos de transição e nas análises (acadêmicas ou não) que acompanharam tais processos. Todavia, como os próprios regimes autoritários enfrentaram terríveis dificuldades de gestão econômica e financeira e as democracias transicionais mostraram mais capacidade de sobrevivência do que se supunha (5), evidenciou-se a necessidade de abordagens mais sofisticadas e abrangentes.

Uma contribuição relevante é a de Laurence Whitehead. Ele acentua a importância das percepçóes do quadro político-econômico pela opinião pública. Outro fator enfatizado por Whitehead é a nitidez da distinçáo entre o pacto formativo constituinte, de natureza políticoinstitucional, e os eventuais pactos e/ou consensos de natureza social e econômica. Para este autor, uma cuidadosa separação entre estas duas modalidades terá efeitos positivos para o êxito da consolidação democrática (6). Por seu turno, Paul Drake quase inverte a "seqüência desoladora" mencionada por Hirschman, ao sugerir que as democracias, portadoras de maior legitimidade, podem enfrentar as crises econômicas com maior resiliência (7). Uma abordagem instigante é a de Jeffrey Frieden, que propóe o uso das conhecidas categorias de Albert Hirschman - "saída" (exit) e "voz" (voice) - para analisar o comportamento dos empresários e dos detentores de ativos em geral no momento da transiçáo marcada por crise econômica e financeira. A opçáo pela "saída" seria, de forma literal, a retirada através da transferência de ativos para fora do País, configurando o capital flight, enquanto a "voz" seria a escolha pela atuação política (8).

Examinando casos concretos - a Argentina de Alfonsín e o Brasil de Sarney -, Juan Carlos Torre (9) e Lourdes Sola (10) apontaram a presença dos resíduos do autoritarismo no policy-making dos regimes de transição democrática. Também salientaram a importância do "aprendizado" por atores políticos e sociais relevantes sobre a natureza de constraints estruturais de natureza econômica e institucional.

O que caracteriza este conjunto de estudos é a busca, freqüentemente bem-sucedida, de conexóes entre a natureza dos regimes políticos $\mathrm{e}$ as modalidades de gestão econômica em meio a situaçốes de crise.

Julgamos pertinente, no entanto, sugerir uma linha de análise que ressalte uma outra dimensão dos processos políticos, usualmente deixada em segundo plano: a da estruturação do poder político náo só como regime, mas também como Estado. A necessidade de incorporar esta distinção já foi apontada com vigor, mas sem muita repercussão, por 
Fernando Henrique Cardoso, a propósito das discussōes sobre o autoritarismo (11).

O conceito de regime diz respeito ao âmbito político-institucional. Refere-se: às regras que ligam os principais centros de poder político (Legislativo, Executivo, Judiciário, sistema partidário e diferentes níveis de poder na Federação); e aos laços políticos que vinculam os cidadáos e a classe política (democracia mais ou menos extensa, oligarquia, etc.). $O$ conceito de Estado diz respeito à articulação entre o poder político e o conjunto do corpo social, isto é, a realidade social perpassada por conflitos fundados em diferenciaçóes interclasses e intraclasse.

Esta distinção analítica entre Estado e regime político é importante, na medida em que o padrão básico de articulação política, isto é, as relaçóes de domínio entre classes e fraçóes de classe, comporta variaçóes consideráveis nas regras pertinentes ao âmbito político-institucional; uma mesma forma de Estado pode se organizar sob vários regimes políticos. No caso da transigão política brasileira, a distinção é crucial porque - como pretendemos mostrar - a crise do regime autoritário é sobredeterminada pela crise da forma de Estado característica da sociedade brasileira desde os anos 30 .

O longo processo de transição política dos anos 70 e 80 no Brasil, a agonia do regime autoritário de base militar e as dores do parto de uma alternativa democrática de base civil ocorreram no interior de um conjunto de crises que demarcam tanto sua natureza como seus impasses.

Estão em crise o padrão anterior de articulação entre capitais locais - privados e estatal - e o capital internacional; a forma existente de agregação e representaçăo de interesses econômico-sociais gerados em uma sociedade cada vez mais complexa; e a relaçáo entre setor público e privado no processo de desenvolvimento capitalista. Tais crises se condensam no núcleo político da sociedade, pondo em xeque náo só o regime que se busca substituir mas a própria forma de Estado, o Estado Desenvolvimentista.

Esta forma de Estado - que não é peculiar ao regime de 1964, já que nasce na década de 30 e se consolida no Estado Novo (19371945) - vem sendo abalada de dois modos. De um lado, tem mostrado crescente incapacidade de absorver em suas estruturas os processos de agregaçáo e representação de interesses econômico-sociais emergentes. De outro, tem perdido progressivamente sua capacidade de nuclear o processo de desenvolvimento capitalista nacional.

No período posterior à Revolução de 1930, o Estado nacional 
procedeu a uma peculiar acomodação entre as oligarquias tradicionais e os novos setores urbanos e industriais em expansão. É típica desta modalidade de Estado intervencionista a capacidade de articular diretamente no interior do Executivo os interesses econômico-regionais e os econômico-funcionais, sejam eles tradicionais ou modernos.

Assim, os interesses ligados ao principal complexo exportador, o cafeeiro, e também os demais setores da agricultura tradicional como os do açúcar, do cacau, do mate e outros passaram a ter uma presença pública nas autarquias e institutos como o Departamento Nacional do Café (depois substituído pelo Instituto Brasileiro do Café), o Instituto do Açúcar e do Álcool, a Comissão Econômica da Lavoura Cacaueira, o Instituto Nacional do Mate, etc.

Além disso, trabalhadores e empresários passaram a vincular-se ao Estado por meio de uma rede de organizaçóes formada pelos sindicatos oficiais, federaçōes e confederaçōes de categoria profissional ou de setor empresarial, e através da Justiça do Trabalho.

Este esmaecimento das fronteiras entre os mundos público e privado, inerente à exacerbação das funçóes do Estado nacional na Era Vargas, sempre dificultou a articulação institucional autônoma dos grupos de interesse (12).

O extraordinário desenvolvimento capitalista, ocorrido a partir do fim dos anos 60 até os anos 80 , impulsionou mudanças socioeconômicas importantes, mas sem modificar o padrão básico (basic pattern) de relação Estado/sociedade. Neste período, ocorreram não apenas alterações significativas na estrutura social, mas também aquilo que Wanderley Guilherme dos Santos chama de "complexificação social", isto é, o surgimento de uma teia de organizaçóes que articulam e dáo identidade coletiva aos agentes sociais, moldam o seu comportamento e veiculam suas demandas. Centenas de associaçóes empresariais, de moradores, de técnicos, de trabalhadores surgiram paralelamente às formas estatais de representaçăo de interesses.

Mesmo quando a forma de articulaçáo de interesses continua estatal, os padróes de conduta já não se subordinam ao Estado. Em suma, a sociedade extravasou o Estado, tornou-se complexa demais para ser absorvida por seus mecanismos de representaçáo e de cooptação. Reciprocamente, a capacidade do Estado controlar e dirigir a açáo dos segmentos sociais tende a reduzir-se progressivamente (13).

Por outro lado, as possibilidades do Estado continuar como articulador do desenvolvimento capitalista nacional, como Estado Desenvolvimentista, foram fortemente diminuídas por um duplo processo: a 
crise fiscal e financeira, que envolve o padrão de financiamento do desenvolvimento, surge entrelaçada com a balcanização do aparelho estatal, ou seja, a progressiva perda de comando da cúpula governamental sobre a multiplicidade de órgáos do setor público (14). Examinemos estes dois aspectos fundamentais.

O primeiro diz respeito à sua capacidade financeira de intervençăo no processo. Desde 1930, o Estado tem funcionado sistematicamente como mecanismo de proteção das várias atividades econômicas existentes no País, frente às vicissitudes dos mercados internacional e nacional. A partir do Estado Novo, o poder público passou a atuar, também, como promotor da diferenciação do aparelho produtivo nacional, ampliando sua capacidade industrial. Neste sentido, existe um parentesco direto entre a implantação da siderurgia pesada em Volta Redonda durante o Estado Novo, a execuçáo do Plano de Metas de Juscelino Kubitschek (1956-1961) e a do II Plano Nacional de Desenvolvimento (PND) de Ernesto Geisel (1974-1979). Para a compreensáo da natureza da relaçáo Estado-sociedade na história brasileira, é estratégico ressaltar a forte continuidade do estilo de atuação do Estado Desenvolvimentista, através de distintos regimes - o Estado Novo, a Constituição de 1946 e o autoritarismo inaugurado em 1964.

Há, hoje, um amplo consenso sobre a importância do II PND como momento da afirmaçáo máxima das características desta forma de Estado e da definição dos contornos da crise atual. Frente ao estrangulamento externo ocasionado pela alta extraordinária dos preços internacionais do petróleo, o governo Geisel desencadeou um ambicioso programa de substituiçáo de importações sob a égide do Estado mas com maciça utilização de empréstimos externos. Esta onda de investimentos na área de bens de capital e intermediários, na qual a distribuição das aplicaçōes orientava-se pelo famoso tripé - capital estrangeiro, nacional e estatal -, amplia a autonomia industrial do País frente ao Exterior. Com isso, as taxas de crescimento do PIB, embora menores que as vigentes nos anos do milagre econbmico (1968-1973), foram ainda elevadas.

Entretanto, a reduçáo conseguida na dependência produtiva teve como contrapartida a elevaçáo da dependência financeira em relaçăo ao mercado internacional de capitais. Enquanto as taxas internacionais de juros mantinham-se relativamente baixas e o preço do petróleo conservava-se no mesmo patamar, o País conseguiu preservar sua capacidade de pagamentos absorvendo novos capitais que permitiam rolar a dívida.

A partir da alta violenta da taxa internacional de juros, em 1979, e da nova elevação do patamar dos preços do petróleo, a capacidade de 
adaptaçáo da economia brasileira ao ambiente econômico internacional foi posta em xeque. Restringiu-se paulatinamente o acesso do Brasil ao mercado internacional de capitais, até a completa interrupçăo dos fluxos voluntários a partir do setembro negro mexicano de 1982 (15).

Estas restriçōes obrigaram a uma redução das atividades econômicas do País. $O$ ajuste recessivo anterior $e$ posterior aos acordos com o FMI teve o condáo de adaptar a economia como um todo para enfrentar a crise da balança de pagamentos. Paulatinamente, foram gerados os excedentes exportáveis necessários ao pagamento do serviço da dívida externa. Nos anos 80 e, especialmente, depois de 1982, o setor capitalista privado se adapta a patamares inferiores de produção, diminuindo celeremente seu endividamento interno e externo.

O setor público teve comportamento diverso. Além da redução drástica do financiamento externo a suas atividades, a capacidade extrativa do Estado, que já fora afetada pela redução do ritmo de crescimento econômico ocorrida a partir de 74, se comprime mais ainda com a recessáo dos anos 80 . Ao passo que, entre 1970 e 75 , a receita tributária bruta situava-se em torno de $26 \%$ do PIB, em 1980 este percentual caía para $24,2 \%$ e em 1985 chegava a $22,1 \%$ (16).

Sitiado pela interrupção das fontes externas de financiamento e pela queda da arrecadaçáo, o ajuste do setor público foi extremamente moderado. Segundo o padráo que vem caracterizando suas relaçóes com o setor privado desde os anos 30, e mais ainda no pós-1967, o Estado manteve-se como rede de proteçáo dos capitais privados absorvendo prejuízos eventuais, incorporando empresas falidas ou suas dívidas; preservando com subsídios e incentivos as formas arcaicas de produção, protegendo-as das forças do mercado; dando condiçóes de implantaçáo e sobrevivência a formas avançadas de produçáo mas à custa de sua auto-sustentação. Deve notar-se que, por um complexo conjunto de mecanismos, a dívida externa foi amplamente estatizada, com o setor público passando a responder por $75 \%$ de seu total.

Outro aspecto central da deterioração da situação fiscal é por vezes objeto de mal-entendidos. A estatização da dívida externa veio acompanhada de um crescimento em espiral da dívida interna, já que o setor público tem que adquirir os dólares gerados pelo setor privado exportador, produzindo um déficit de grandes proporçóes. Como colocaram Silveira e Bielschowsky, "o financiamento deste déficit, via dívida interna, tem gerado um processo de substituiçáo de endividamento externo por endividamento interno, responsável em grande medida pelo crescimento extraordinário deste" (17). 
Além disso, o setor público continuou sendo usado, especialmente nos âmbitos estadual e municipal, como instrumento de clientelismo. Neste sentido, o ano de 1982 foi típico. Em plena recessão e no ápice da crise do balanço de pagamentos, os governos estaduais aumentaram drasticamente o seu pessoal, na busca da vitória nas eleiçóes de 15 de novembro.

Em suma, o que desejamos salientar é a relevância da característica básica da forma especial do Estado intervencionista que se construiu desde 1930, que é seu caráter de vanguarda do desenvolvimento e de protetor do atraso, na feliz expressão de José Luis Fiori (18). Ao procurar a impossível compatibilização de uma multiplicidade de papéis em um momento de crise internacional, o Estado mergulha em uma crise fiscal que é a manifestação de um impasse político básico. Ao procurar manter à tona todos os heterogêneos setores do bloco de poder soldado no regime autoritário, o Estado tende a desgastar-se frente a todos. Neste contexto, o endividamento público interno surge como a válvula de escape à maré montante de pressóes, no sentido da manutençáo da lucratividade privada e da conservaçáo do desenho tradicional do aparelho de Estado.

A interrupção dos fluxos externos de capital, a redução de capacidade extrativa e a ampliação do endividamento público externo e interno reduziram radicalmente a capacidade do Estado desencadear qualquer nova onda de inversóes que canalizasse investimentos privados para tal ou qual setor. A poupança líquida do setor público cai vertiginosamente de $4,67 \%$ do PIB em 1975 para 2,24\% em 1980, tornando-se negativa em 1985. Os investimentos públicos, que correspondiam em 1975 a $4,1 \%$ do PIB, caíram para $2,3 \%$ em 1985 , pequena taxa ainda assim mantida graças a um déficit de $3,08 \%$ em relaçăo ao PIB (19).

Estiolaram-se, aos poucos, as possibilidades do setor público induzir positivamente o sistema econômico. O Estado vê-se, cada vez mais, prisioneiro da necessidade de servir à própria dívida. Em 1985, os juros da dívida pública, externa e interna, já alcançavam mais de $10 \%$ do PIB e, não fora a emissão de novos títulos, o seu pagamento deveria consumir mais de $\mathbf{5 0 \%}$ da receita do setor público. Por esta via, pode-se dizer que o conjunto dos capitalistas privados manieta o Estado com a propriedade dos títulos da dívida. Este controle, no entanto, conduz náo à ampliação dos horizontes do capitalismo, mas à estagnação, pois torna passivo o que até há pouco era o seu núcleo motor.

O segundo aspecto, referente à perda da capacidade do Estado nuclear o processo de desenvolvimento, diz respeito à dimensão propriamente política das atividades econômicas estatais. Trata-se do enfra- 
quecimento das relaçốes de domínio entre a cúpula do Estado e aquela parte do quadro administrativo que comanda as empresas estatais. Foi através da administração descentralizada que o poder público se expandiu economicamente no pós-64. A empresa - pública ou de economia mista - foi a forma institucional básica por meio da qual o regime militar aprofundou de modo extraordinário a participaçáo estatal nas atividades produtivas. As relaçóes entre as várias instâncias da administração pública, consubstanciadas no Decreto-Lei no 200, de 1969, resultaram em crescente autonomia gerencial das empresas estatais em relação ao poder central. Elas passaram a se conduzir, não como entidades públicas subordinadas a um interesse geral, definido em centros de poder mais elevados no interior do Estado, mas como corporaçóes privadas, cujos interesses são, no mínimo, a autoconservação e, se possível, a expansão máxima (20).

Enquanto o Executivo federal manteve uma política compatível com os impulsos de crescimento e diversificação das atividades das empresas estatais, estas não ofereceram resistência às suas diretrizes mesmo aquelas que pudessem prejudicá-las a longo prazo, como a de ampliarem o seu endividamento externo em nome da preservaçáo das reservas nacionais em moeda estrangeira. Logo que o padrăo de financiamento da economia entrou em colapso, com a reversão do ciclo econômico, e o governo central tentou impor certa disciplina às atividades de suas empresas, estas passaram a oferecer tenaz resistência aos seus comandos (21).

As dificuldades econômicas dos anos 80, a fragilização do Estado, especialmente a reduçáo de sua capacidade econômica de condução do sistema capitalista nacional, tiveram um papel importante na forma pela qual se deu a desagregação final do regime militar e, por esta via, nas condições políticas legadas ao governo que se instaurou em 15 de março de 1985.

A transição política do governo militar para o governo civil teve como marca fundamental, como já foi salientado muitas vezes, não ter envolvido ruptura da ordem institucional. A ordem jurídico-política sob a qual nasceu o primeiro governo civil, a chamada Nova Repuiblica, foi substancialmente a mesma legada pelo regime militar no período do governo Figueiredo (1979-1985), já sem o Ato Institucional n² 5, mas com a presença dos mecanismos de proteçáo do Estado, como a possibilidade de decretar medidas e Estado de Emergência.

A ordem institucional característica do regime saído do golpe militar de 1964 pode ser esquematizada pelos seguintes traços: quanto à forma de governo, por um presidencialismo exacerbado, de base mi- 
litar, tendo o Parlamento e os partidos funçóes governativas quase nulas e funçōes representativas extremamente viesadas e limitadas; quanto à distribuição do poder entre os diferentes âmbitos de governo, pelo peso desproporcional da União em relaçáo a estados e municípios da Federação; quanto à relação governantes/governados, por uma participaçáo obviamente muito reduzida do conjunto da populaçāo, tanto pelas restriçốes à sua intervenção eleitoral como pelas grandes distorçōes na representação política.

A manutençáo da legalidade náo implicou, entretanto, em preservar a identidade do regime até o fim. Ele foi perdendo densidade aos poucos, minguando enquanto exercício prático do autoritarismo, ao longo do ambíguo período Figueiredo. $O$ governo federal foi deixando paulatinamente de utilizar, na sua plenitude, as possibilidades de poder inscritas no plano jurídico, ao passo que outros centros de poder no interior do regime ganharam mais peso do que anteriormente.

Este processo acelera-se a partir de 1983. A realizaçăo das primeiras eleiçóes diretas para os governos estaduais em 82 e a expectativa de que o processo de abertura política prosseguiria sem retrocessos abalaram a hierarquia existente entre os vários centros de poder político. Passam a existir distintos pólos de poder, com diferentes graus de legitimidade; os partidos de oposiçăo, especialmente o maior deles, o $\mathrm{PMDB}$, ampliam sua esfera de atuação e dispóem, agora, dos recursos de poder proporcionados pelos governos estaduais. $O$ governo federal e, particularmente, a Presidência da República perderam sua quase exclusividade como grandes eleitores nos estados. $O$ julgamento futuro do eleitorado converteu-se em interesse básico de cada governador estadual. Em outras palavras, não só para os governadores oposicionistas a maioria dos eleitos naquele ano -, mas também para os ligados ao PDS, partido de sustentação do governo militar, satisfazer o eleitorado tornou-se condição de sobrevivência política.

O rompimento do esquema de controle do poder central sobre a Federação também afetou a conduta política do Congresso Nacional. Este ganhou autonomia porque deixou de enfrentar um Poder Executivo monolítico, com um quase monopólio dos recursos políticos disponíveis, passando a se defrontar com múltiplos centros de poder, desiguais em recursos, mas concorrentes.

É claro que, consideradas no plano estritamente político, as fissuras apontadas seriam apenas potenciais. As tensóes na Federaçáo e entre Executivo e Legislativo poderiam ser minimizadas caso o poder central dispusesse de recursos para satisfazer os interesses dos aliados e para cooptar adversários. É possível que isto ocorresse caso o País esti- 
vesse no ápice do ciclo econômico, a União dispusesse de arrecadação tributária farta e fossem boas as perspectivas de ampliaçáo do endividamento do setor público. Como vimos, a situação era exatamente a oposta.

A fragilização do Estado pôs a descoberto as rachaduras no edificio político do regime. A reduçáo da capacidade financeira do Estado, proveniente da crise, aprofundou as divergências político-partidárias já existentes e debilitou o esquema de sustentaçáo política regional e parlamentar do governo federal. Isto resultou, já em 1983, numa redução da capacidade de resistência do regime às demandas dos assalariados e aos particularismos regionais e locais, como se constata pelas concessóes que o Executivo federal teve que fazer em termos de política salarial e distribuição de tributos da União para estados e municípios. Recorde-se que em setembro daquele ano, pela primeira vez na história do regime militar, o Congresso Nacional recusou aprovaçáo a um Decreto-Lei, o de $\mathrm{n}=\mathbf{2 . 0 4 5}$, que aumentava $\mathrm{O}$ arrocho salarial.

Em síntese, no processo de transição política brasileira o quadro jurídico-institucional préviö permaneceu, mas a forma de atuação do regime foi sendo paulatinamente esvaziada de seu conteúdo autoritário. Centros institucionais de poder antes subalternos, como partidos, Congresso Nacional, executivos estaduais, etc., foram ganhando autonomia em relaçáo ao poder central e maior representatividade popular. No fim do governo Figueiredo, restava uma Presidência da República imperial, do ponto de vista legal, mas de fato com reduzida capacidade de comando sobre os quadros políticos do regime, especialmente os civis. No Parlamento e nos estados já se tramava a teia do futuro (22).

Esta perda de capacidade de comando do governo central e a autonomização do Congresso Nacional e dos governos estaduais consolidam-se no processo sucessório que encerrou o ciclo de presidentes militares.

Têm-se enfatizado seguidamente, e com razão, as funçóes conservadoras do processo indireto de escolha do presidente da República. A manutenção da legalidade - Colégio Eleitoral restrito, definido pela reforma constitucional de 1982 - , apesar de sua reduzidíssima legitimidade popular, tinha um conteúdo óbvio: dava sobrevida a uma das características básicas do regime, a participação popular limitada no processo político. Além disso, na conjuntura, a preservação da regra eleitoral teve uma funçáo específica, ao impedir a participação da maioria da populaçăo no processo sucessório. As massas populares e camadas médias urbanas, já mobilizadas pela campanba das diretas, viram-se excluídas, logo após o maior movimento de opinião conhecido na história 


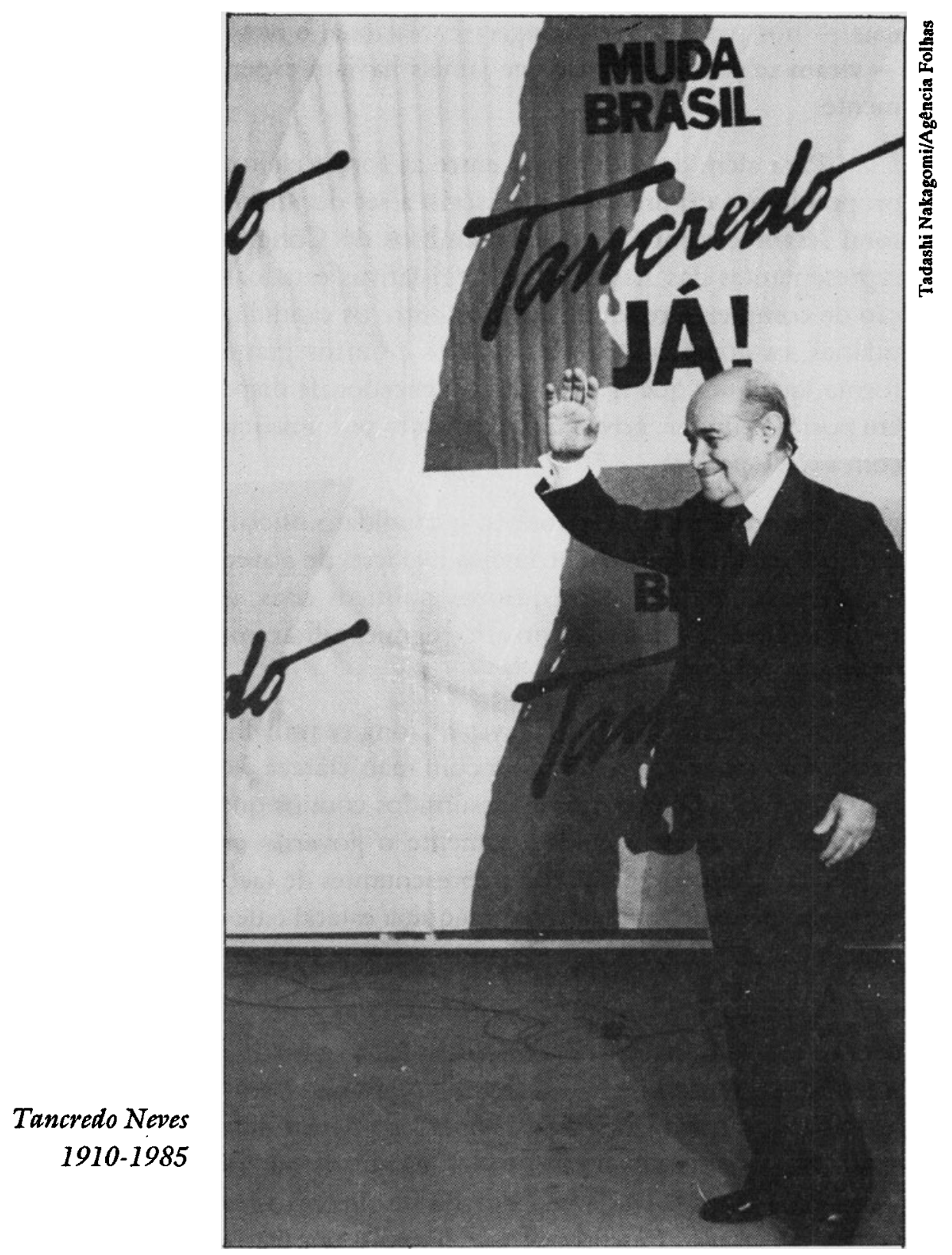

do País, com reivindicações que expressavam exigências de democracia política e social. Desta forma, foi reduzido ao máximo o impacto reformista que teria a intervenção popular no processo de transição.

Por outro lado, também houve funções inovadoras desta eleição presidencial indireta. À medida que o presidente da República náo conseguiu obter ou impor consenso entre as forças políticas do regime, e que os militares recuaram para os bastidores fazendo da preservação da legalidade autoritária o bastiáo de sua unidade, os políticos profissio- 
nais - nos partidos, no Congresso Nacional e nos governos estaduais - viram-se com um poder que jamais haviam experimentado anteriormente.

Para além das diferenças entre as forças eleitorais em presença, a própria lógica do processo sucessório a ser decidido num Colégio Eleitoral restrito, composto pelos membros do Congresso Nacional e por representantes das Assembléias Legislativas estaduais, levou à elaboração de complexas redes de acordos entre os candidatos, as cúpulas partidárias, os governadores dos estados e outros grandes eleitores. Desta forma, qualquer que tivesse sido o vencedor da disputa, encontrar-se-ia em posiçáo similar: governaria amarrado por uma teia de compromissos com a classe politica.

Caso tivesse sido vitorioso o candidato oficial, Paulo Maluf, certamente cobrar-lhe-iam a promessa explícita de governar com o partido, de dar peso no futuro aos quadros políticos civis, que até entấo cumpriam a função de mero suporte do regime militar, mas sem ter qualquer comando sobre ele.

A vitória de Tancredo Neves e a longa e trabalhosa gestação de seu ministério permitiu-lhe perceber com mais clareza a extensão e, em parte, a lógica dos compromissos assumidos com os que o apoiaram. Tancredo Neves repartiu cuidadosamente o governo entre seus eleitores, tendências político-partidárias, representantes de faç̧óes políticas regionais, agrupamentos sediados na máquina estatal e de controle da opiniāe pública (23).

Graças a um cuidadoso trabalho de engenharia política ao longo de 1984, a cisão do partido oficial, o PDS, e o surgimento de sua dissidência, a Frente Liberal, abriram o caminho para sua vitória no Colégio Eleitoral, em janeiro de 1985. Caso tivesse sido empossado, Tancredo Neves teria governado sob a legalidade anterior, ocupando portanto uma Presidência ainda dotada de dimensóes imperiais. No momento da vitória, esperava-se que o apoio popular que legitimava implicitamente sua candidatura (como admitiam, aliás, até os setores de oposição que não tinham participado da eleiçáo indireta) pudesse fazer da Presidência um instrumento de transformação. Haveria uma curiosa combinaçáo da institucionalidade do autoritarismo com a legitimidade quase plebiscitária que o movimento pelas diretas proporcionara às forças de oposição ao regime. Entretanto, Tancredo não pairava acima das forças políticas que o conduziram à vitória. Ao contrário, ver-se-ia na contingência de exercer o poder em conformidade com elas. Na doença e na morte, Tancredo fora de tal forma endeusado, como profeta da 
construçáo da democracia e da reforma social, que se chega a esquecer como ele fora o líder e principal articulador de uma complexa rede de alianças em que coexistiam conservantismo e transformaçăo, continuidade e mudança.

Com o falecimento de Tancredo Neves e a posse do vice-presidente, José Sarney, a ambigüidade implícita nesta situaçăo foi exacerbada ao extremo. A presença, na chefia do Executivo, de um representante dos quadros civis do regime autoritário fez do distanciamento entre as potencialidades da Presidência como instituição e o poder efetivo de seu ocupante o problema central da dinâmica política da transição. A precariedade da Alianfa Democrática entre o PMDB e a Frente Liberal, apesar de sua aparente maioria parlamentar, logo se evidenciou nas dificuldades de encaminhamento de quaisquer reformas além dos limites do que foi denominado "remoção do entulho autoritário" (24).

Este conjunto de antecedentes sobre a natureza da crise do Estado desenvolvimentista $\mathrm{e}$ as peculiaridades da forma assumida pelo processo de transiçáo política nos proporcionam subsídios para a análise dos im passes e dilemas da Nopa Repríblica. Já tratamos, em outra parte, das características dos diversos momentos de política econômica do período Sarney, com seus quatro ministros da Fazenda e três planos de estabilização (25).

Aqui nos importa examinar a configuraçăo de um impasse reiterado, de um loop que condiciona e limita as alternativas de política econômica, entendida em sentido amplo (26). Impossibilitado de exercer seu papel histórico pela limitação fiscal, manietado pelos credores externos e internos, penetrado em seu próprio aparelho pelo imenso conjunto de particularismos e corporativismos, o outrora poderoso Leviathan debate-se numa teia imobilizadora frente à ameaça da hiperinflação.

Tem sido apontada a existência de um amplo consenso, para além das querelas entre os economistas acadêmicos, sobre a natureza da crise (27). Tal consenso, talvez ainda em construçáo, seria uma confirmação a mais do ponto central de nossa argumentação: o que está em jogo na crise econômica brasileira é a constituiçáo de um pacto político que abra o caminho não só para a construção de um novo regime, mas também para uma reformulaçáo do próprio Estado.

\section{Notas}

1 Para uma sintese, ver Guillermo O'Donnell \& Philippe Schnitter, Transitions from authoritarian rule-tentative conclusions, Baltimore, Johns Hopkins Press, 1986. 
2 Para uma discussāo dos anos 80, ver CEPAL, Transformación productipa con equidad, Santiago de Chile, Naciones Unidas, 1990.

3 Alguns economistas brasileiros fizeram esforços para incorporar a dimensão política em suas análises. Ver Amaury Bier, Roberto Messenberg e Leda Paulani, O heterodosco co pós-moderno: o cruzado em conflito, São Paulo, Paz e Terra, 1987; Rui Affonso, Plinio Sampaio Jr. \& Gilson Schwarz, "Política económica e democratização, " in Fábio Wanderley Reis \& Guillermo ODonnell, $A$ democracia no Brasil - dilemas e perspectivas, São Paulo, Vértice, 1988 e também Guilherme Silva Dias \& Basilia M. Aguirre, Transifăo económica e ingopernabilidade, mimeo., Instituto de Estudos Avançados da USP, 1990.

4 Albert Hirschman, $A$ economia poltica do desenpolvimento latino-americano, Revista Brasileira de Ciências Sociais, no 3, fevereiro de 1987.

5 Ver Robert Kaufman \& Barbara Stallings, "Debt and democracy in the 1980s", in . Barbara Stallings \& Robert Kaufman (eds.), Debt and democracy in Latin America, Boulder, Westview Press, 1989.

6 Laurence Whitehead, The consolidation of democracy, mimeo., Oxford, 1985.

7 Paul Drake, "Debt and democracy in Latin America, 1920-1980 ", in Stallings \& Kaufman, op. cit.

8 Jefrey Frieden, "Winners and losers in the latin american debt crisis: the political implications", in Stallings \& Kaufman, op. cit.

9 Juan Carlos Torre, Transicion democratica y emergencia economica, mimeo., Buenos Aires, 1988.

10 Lourdes Sola, "Limites políticos ao choque heterodoxo no Brasil", Revista Brasileira de Ciências Sociais, $\mathrm{n} \% 9$, fevereiro de 1989.

11 Ver a contribuiçăo de Cardoso ao volume coletivo editado por David Collier, The new authoritarianism in Latin America, Princeton, Princeton University Press, 1979.

12 Esta caracterização bem como parte dos irens II e III reelaboram texto anterior de Brasilio Sallum Jr. "Por que não tem dado certo: notas sobre a transição política. brasileira", in Lourdes Sola (ed.), O Estado da Transiçäo - politica e cconomia na Nova Repriblica. São Paulo, Vértice, 1988. As especificidades do padrāo de relacionamento Estado-sociedade que emergiu no Brasil pós-1930 foram analisadas por Maria do Carmo Campello de Souza, Luciano Martins e Sônia Draibe.

13 Ver Wanderley Guilherme dos Santos, "Cidadania e Justiça", Rio de Janeiro, Campus, 1978.

14 Ver Luciano Martins, "Estado capitalista e burocracia no Brasil pós-64", Rio de Janeiro, Paz e Terra, 1985.

15 Sobre o período Geisel, ver Antônio Barros de Castro \& F. E. Pires de Souza, "A economia brasileira em marcha forçada", Rio de Janeiro, Paz e Terra, 1985.

16 Silvio Rodrigues Alves, "Por que o governo é deficitário", Folha de S. Paulo, $13 / 2 / 1988$.

17 Caio Silveira \& Ricardo Bielschowsky," Introdução ao pensamento econômico brasileiro atual: o debate da retomada" , Boletim da Conjuntura, Universidade Federal do Rio de Janeiro, 1986.

18 Ver José Luis Fiori, "Conjuntura e ciclo na dinâmica de um estado periférico" , USP, tese de doutorado mimieografada, 1985. 
19 Silvio Rodrigues Alves, op. cit.

20 A Petrobrás, por exemplo, preferiu investir no Exterior a priorizar a prospecçāo de petróleo no território nacional.

21 A SEST, órgão criado em 1979 para controlar as empresas estatais, teve dificuldades até para obter dados destas mesmas empresas.

22 Isto demonstra que a distinção entre uma ordem autoritárià institucionalizada e uma prdxcis autoritaria pode ser relevante para a análise. Para um ponto de vista diverso, ver Wanderley Guilherme dos Santos, "Ordem burguesa e liberalismo político", São Paulo, Duas Cidades, 1978.

23 Ver Brasilio Sallum Jr., Carlos Estevam Martins \& Eduardo Graeff, "Nova República, de Tancredo Neves a Sarney", Análise Conjuntural (Especial), v. 8, no 2, fevereiro de 1986, IPARDES, Curitiba.

24 Ibidem.

25 Brasilio Sallum Jr. \& Eduardo Kugelmas, "Política econômica em sursis", mimeografado, ANPOCS, 1988.

26 Agradecemos a Luiz Aureliano de Andrade por nos ter sugerido a imagem do loop.

27 Ver Guilherme Silva Dias \& Basilia Aguirre, op. cit.

\section{Resumo}

Este artigo faz um balanço da crise brasileira dos anos 80 . Busca analisar a interaçāo entre crise econômica e transformação política, enfatizando a importância da distinçăo conceitual entre Estado e regime político. Usa sistematicamente tais conceitos para explicar a natureza da crise $\mathbf{e}$ as dificuldades da transição para a democracia. E salientada a ruptura das alianças que sustentaram o velho Estado desenvolvimentista surgido nos anos $30 \mathrm{e}$ a extensão das dificuldades que retardaram a emergência de um novo pacto hegemónico.

\section{Abstract}

This article evalvates the Brazilian crisis in the Eighties, analysing the feedback between economic crisis and political change. Its approach emphatizes the importance of the difference between the concepts of State and political regime. These two concepts are used in a systematic way to explain the nature of the crisis and the difficulties of the transition tomards democracy. The rupture of the alliances that supported the old developmental State of the thirties in undescored, as well as the extent of the difficulcies that delay the emergence of a new hegemonic pact.

Brasilio Sallum Jr. é professor do Departamento de Sociologia da FFLCH-USP.

Eduardo Kugelmas é professor do Departamento de Ciência Política da FFLCH-USP.

Trabalho apresentado no seminário "Estados, Mercados e Democracias", organizado pela Área de Política e Economia do IEA, com o apoio dos Departamentos de Sociologia e Ciência Política da FFLCH-USP e do Departamento de Economia da FEA-USP, de 28 a 31 de julho de 1991, em São Paulo. 